Article

\title{
Oxcart Route in the City: Tracking the Urbanization Process of an Agricultural Village in Korea
}

\author{
Kyung Wook Seo ${ }^{1} \mathbb{C}$ and Sugie Lee ${ }^{2, *}$ \\ 1 Department of Architecture \& Built Environment, Northumbria University, Newcastle upon Tyne NE1 8ST, \\ UK; kyung.seo@northumbria.ac.uk \\ 2 Department of Urban Planning \& Engineering, Hanyang University, Seoul 04763, Korea \\ * Correspondence: sugielee@hanyang.ac.kr
}

Received: 24 February 2019; Accepted: 3 April 2019; Published: 11 April 2019

check for updates

\begin{abstract}
In this research, we traced the process of urbanization of a small agricultural village in Korea through the massive construction of housing estates and the modern street network in the late 20th century. Whereas the existing literature tends to adopt a data-driven macroscopic approach to analyze periurban transformation, we concentrated on the morphological transition of old rural roads in a small village to provide a microscopic interpretation of how they are obliterated, fragmented, or preserved in relation to land types and the acquisition process. Through a careful investigation of various maps and archives, we found that the woodland was the main target for development. In contrast, clustered residential plots were the most enduring feature that resisted change, entailing that their internal route remained intact. To determine the potential benefit of an irregular old route within the modern block, network analysis was executed to measure its performance. The route was shown to provide efficient movement in the current system, especially within the scale of the old village. The preservation of old spatial legacy, therefore, helps assign historical, social, and practical meaning to the design a sustainable modern city.
\end{abstract}

Keywords: urbanization; periurban development; rural routes; modern network; land types

\section{Introduction}

Urbanization implies both growth and condensing of the built environment. When it is gradual, the intervention of new buildings and roads often mingles with the existing landscape. When it is radical, however, the old spatial memory can be obliterated. In other words, once laid under the force of mega-scale developments, it is difficult to protect the legacy of natural and man-made environments that evolved over many generations. Major arterial roads re-frame the boundary of the area and externally impose a new spatial order. Once the internal road network is laid, the land is subdivided for land use zoning. When the process occurs rapidly and thoroughly, the original form of the townscape is obliterated. In some cases, however, old spatial elements evade the change and remain intact. The most common element of these is old roads in major cities. It is these fragments from the past that this research focuses on as a clue to trace the typical process of urbanization in Korea in the late 20th century. Against the intention of modern planners, these roads made their way into the modern grid with their organic pattern. What are the driving forces behind the persistence of old roads in the urban setting? Furthermore, what influences their morphological transition to fragmentation or demise?

Many cities in South Korea went through a radical transformation during the late 20th century, driven by the national agenda of economic growth and modernization. In particular, the Seoul metropolitan area (SMA), including the capital city of Seoul, Incheon city, and Gyeonggi province, has been the center of economic growth and rapid urbanization, with significant increases in population 
since the 1960s [1]. With explosive population growth from 8.7 million in 1970 to 13.3 million in 1980 [2], the Korean government has had to address the problems of housing shortages and the real estate bubble. As a result, the Korean government initiated housing and land development in the 1980s and new town development in the 1990s, expanding the SMA into surrounding small towns and rural villages [3]. The spatial expansion of the SMA accelerated the urbanization of surrounding agricultural periurban areas.

Urbanization accompanies territorial expansion and inevitably results in the consolidation of small villages on the urban periphery. Despite difficulties in defining periurbanization [4], García-Ayllón explained it as "the process of growth for demographic, building, and economic activity that occurs in the periphery of cities" [5]. As Smith pointed out, urban scholars and policymakers should pay attention to the phenomena of periurbanization because rapid homogenization of urban periphery eliminates sources of diversity and dynamism that could be invaluable assets for future sustainability [6].

Many studies have explored the phenomena of periurban transformation in terms of causes and consequences [7-13]. Seto et al. conducted a meta-analysis of global urban land expansion and concluded that urban land expansion is driven by different mixes of factors, including demographic and economic factors [9]. This finding is also supported by an international case study in Northeast China [7]. Similarly, Tian et al. examined the expansion of periurban areas and their social-economic characteristics in Shanghai between 1990 and 2009 [11]. Using spatial analysis of Landsat TM images and land use maps, this study concluded that state-led growth played a dominant role in the expansion of non-agricultural land in Shanghai's periurban areas. Regarding the consequence of periurbanization, Kontgis et al. argued that periurban areas in Southeast Asia would accommodate more than 200 million people by 2030, creating the largest and most significant land cover changes in the region [8]. Using remote sensing and population information for the Ho Chi Minh City metropolitan area in Vietnam, this study indicated that $66 \%$ of urban expansion and $50 \%$ of population growth occurred in periurban communities between 1990 and 2012. In contrast, some studies focused on rapid escalation of land values through the valuation of landscape amenities in the process of periurbanization. Shatkin explained the process of periurbanization in Asia from the perspective of a political economy based on government land monetization [14]. This study also argued that rapid escalation in land values is one of the fundamental driving forces shaping contemporary periurban political and spatial change in Asia.

On the other hand, some studies focused on the spatial analysis of periurban transformation patterns through geographic information systems (GIS) and remote sensing [7,15-18]. Those studies largely addressed the spatial changes of periurban areas with GIS evaluation and territorial indicators. Huang et al. examined the transition of Taipei's periurban zone using remote sensing technologies with SPOT images and eight landscape metrics; they suggested integrated planning strategies for both urban and non-urban planned districts to overcome urban sprawl in periurban areas [16]. Similarly, García-Ayllón suggested useful territorial indicators for predictive diagnosis of agricultural periurban areas in the Mediterranean Southeastern area of Spain [15]. In contrast, Statuto et al. suggested descriptive approaches to analyze rural landscape changes in Southern Italy using historical maps within a GIS platform [18]. Their study illustrated the usefulness of historical documents and current maps to evaluate the multi-temporal and morphological variations in rural landscape.

Thus, existing studies focused on periurbanization in various geographical locations and demanded policies for proper management of periurban areas for future sustainability. However, as Rauws and de Roo pointed out, underlying periurban developments are not susceptible to the influence of planning agencies due to the complex nature of periurban areas and their transitional status between urban and rural [19]. Furthermore, most existing literature on periurbanization focused on the spatial transformation of periurban areas at the macroscopic scale. Hence, little research has been conducted on the transition of periurban areas at the microscopic scale in terms of urban form and morphological perspectives. 
The primary components of urban form are streets, buildings, lots, and blocks. These elements are universal regardless of time and space [20]. However, urban form varies based on the organizations of these elements. Also, urban form depends on the natural environment, socioeconomic conditions, cultural and political situations, and various activities of stakeholders over time. Urban morphology, in general, deals with origins and processes of urban form. Marshall and Çalişkan summarized the various definitions of urban morphology [21]. According to their summations, urban morphology, in general, is "the study of urban form" [22] and "the science of form, or of various factors that govern and influence form" [23]. In addition, the Urban Morphology Research Group defines urban morphology as "the study of the physical (or built) fabric of urban form, and the people and processes shaping it" [24]. Moudon defines urban morphology as "the study of the cities as human habitat" in the contexts of social and economic forces over time [25]. Thus, urban form is the cumulative spatiotemporal outcome of activities of various agents.

Much research on the evolution of urban form has been conducted in the domains of architecture and urban planning. In the seminal study of "Alnwick, Northumberland-A Study in Town-Plan Analysis," Conzen showed the evolution of built-up areas with "types of plan-units" over time, identifying distinct components of built-up areas such as streets, plots, buildings, and blocks [20]. This study provides theoretical and analytical foundations to analyze urban form and its changes over time. Oliveira indicates four components of urban form comprising natural context, the street system, the plot system, and the building system [26]. The characteristics of urban form depend on the organization of those four elements. Also, socioeconomic, cultural, institutional, and political environments affect the organization of these elements over time. Oliveira also implies the importance of different agents and their various contributions in the evolution of urban form. Those agents include developers, architects, builders, planning officers, and politicians who play substantial roles in the decision-making process of urban development.

Kostof explains the primary elements and their roles in shaping urban form from a different viewpoint [27]. According to him, the determinants of urban form are natural topology, land division, synoecism (i.e., administrative arrangements), and law and social order. In particular, he states that "pre-urban land division may well be the most fundamental determinant for the irregular city-forms of all ages". It is true that land division and street system have significant impacts on the basic skeleton of urban form. Similarly, Kropf indicates the importance of "control" in the evolution of urban form [28]. Control is "a socially established relationship between a person or group and a particular objects or area of land, often in the form of ownership". This argument indicates that land ownership should not be ignored in the examination of urban form.

Influenced by urban morphological studies in Western counties, some Korean researchers examined the characteristics of historical urban form in the city center area of Seoul. Jin \& Ahn classified the types and characteristics of historical urban form change in the city center area of Seoul [29]. Their study indicates that while old urban aspects remained in small areas, many of them have been eradicated by merging of lots, widened or constructed roads, and redevelopment. Also, their study pointed out the importance of types and characteristics of historical urban form for urban regeneration. Along similar lines, Kim et al. examined the characteristics of the urban form changes in the old city area of Seoul under the pressure of rapid urban redevelopment [30]. Using the analysis framework suggested by Conzen [20], Kim et al. focused on the transformation of four elements of urban form in terms of streets, lots, buildings, and land use. They argued that the changes in streets and lot spaces are the primary driving forces of urban form transformation in the old blocks of Seoul. Finally, they suggested policies to preserve historical urban characteristics and place uniqueness in old blocks of Seoul.

Although these studies tried to explain the process and determinant factors of urban transformation for old city areas in Seoul, they could not fully explain why some old roads still exist under the high pressure of urban redevelopment. Furthermore, little attention was given to examining how rural roads in the outskirts were influenced during the large-scale urban expansion. 
Among his components of urban morphology, Conzen indicated that street systems are the most resistant to transformation because of public ownership [20]. In contrast, buildings and lots could be easily transformed into different forms over time. His observation may provide some useful insight regarding the existence of old roads in the middle of large-scale urban developments. Along with the importance of public roads, land ownership and land division should be considered in the characteristics of urban form. Complex land ownership of small-scale lots complicates large-scale urban development due to the barriers of coordination. However, these assumptions have not been fully examined in the literature on urban form and determining factors.

This paper, therefore, addresses the issue of periurban transformation at the microscopic scale by focusing on a small agricultural village with three research objectives. First, we traced the process of morphological change in the case study area to determine why some old roads remain while others disappear. Second, we established the relationships between the socioeconomic factors of land types and the pattern of large-scale land acquisition for developments that lead to the obliteration of old roads. Third, we investigated the usefulness of the remaining old roads in the urban setting through observation and network analyses to re-evaluate their practical value in the modern environment.

\section{Materials and Methods}

Following the research question and objectives described above, this chapter defines the case study area and research methodologies. Focusing on a small urban block which used to be a small agricultural village, two different methods were applied to investigate the changes in the past and the network performance in the present. First, through the archival investigation and mapping, the relationship between land types and estate developments was investigated. Second, quantitative methods of static snapshots and a network analysis were executed to measure the usefulness of old roads that survived radical developments.

\subsection{Case Study Area}

Suwon is the seventh largest city in South Korea; it has a population over 1.2 million as of 2016 in its $121.05 \mathrm{~km}^{2}$ area [31]. It has 29 towns including Wooman, which has 42,000 residents. Figure 1 shows the location and the boundary of the case study area, which is one of seven blocks in current Wooman. This area was the original Wooman, when it was a small agricultural village on the outskirts of the city of Suwon. Until 1974, the population was only 1300, and the majority lived in farmhouses [32]. It seems that this particular village raised many oxen, as its name Wooman literally means "many oxen." There are commercial buildings along the major roads in the South and the East, but the block mainly consists of residential buildings. There are six apartment housing estates built in the 1980s and the 1990s occupying large areas of the block. Smaller plots are filled with other types of residential buildings, i.e., low-rise flats, multi-family houses, and detached houses. From the outside, the area looks as a normal urban block with a parallel street network, but from the inside, there appear organic shapes of meandering alleys that seem to come from the past (Figure 2). It is this coexistence of the modern network and the old roads that this research focused on. 


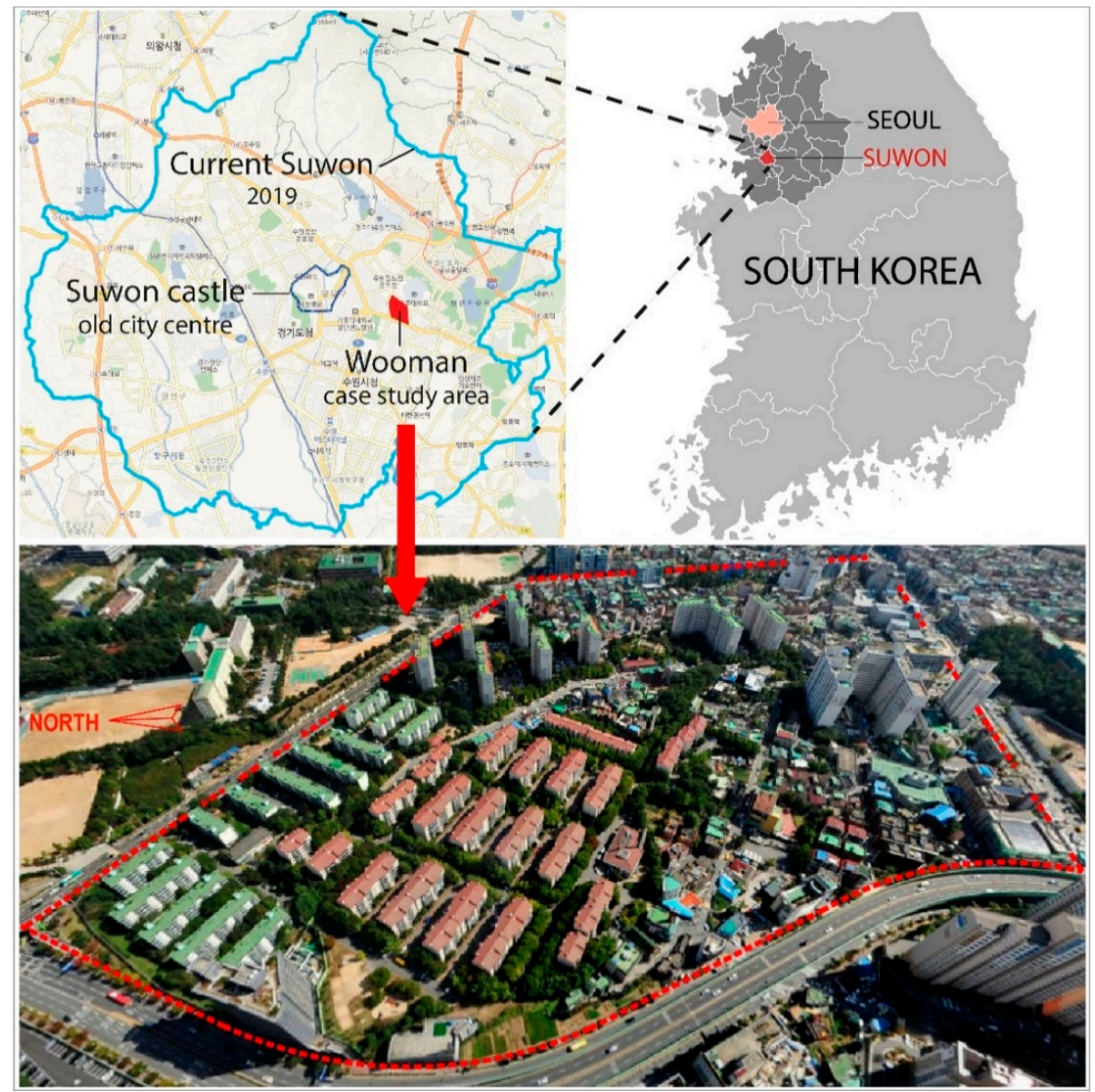

Figure 1. Case study area which was the original area of old Wooman-source: the top-left and bottom images from Daum map, http:/ / map.daum.net; the top-right image by Dmthoth-File: Administrative divisions map of South Korea.svg (Dmthoth), CC BY-SA 3.0, https:/ / commons.wikimedia.org/w/ index.php? curid=24501678.

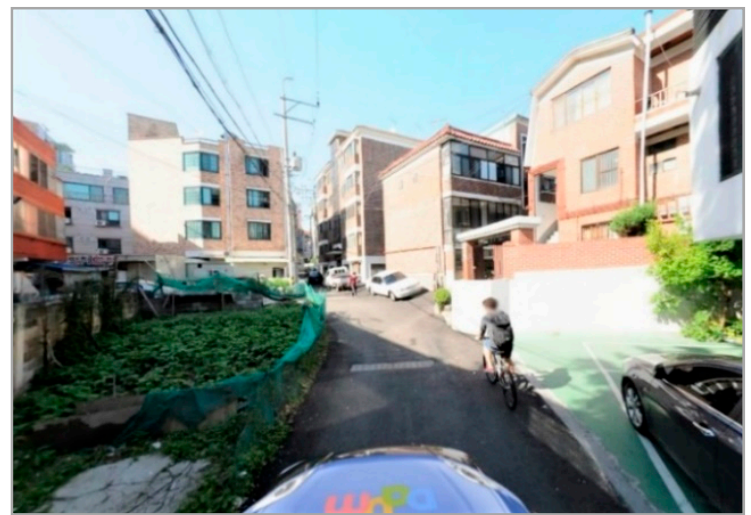

(a)

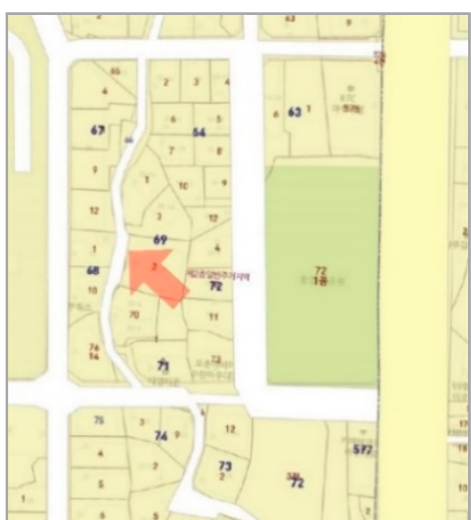

(b)

Figure 2. Organic shape of a back alley in Wooman: (a) Photo taken in May 2013—source: Daum map, http:/ / map.daum.net; (b) Its position on the cadastral map—source: Daum map, http:/ / map.daum.net.

\subsection{Archival Investigation and Mapping}

Efforts have been made to find relevant data and maps to investigate how the shape of the town has changed. As we are focusing particularly on a small agricultural village on the outskirts, it was impossible to secure precise data and maps of the case study area. Until the early 1990s, the local authority of Suwon only produced maps and data manually, and they were concentrated on the central 
area of the city. Therefore, the only available maps showing the earliest landscape were a cadastral map produced in 1971 and a topographic map produced in 1974. Due to the manual production methods, these two archival maps did not exactly match each other, complicating the process of mapping them onto the modern digital map.

Figure 3 shows a part of the oldest cadastral map of Wooman, all hand-drawn and hand-written. It recorded both the original state of land registration in 1971 and later changes up to 1985 by overlaying updates in a cumulative way. When land use changed, the existing label was crossed out with double lines, and a new label was added next to it. The original land use was written in Chinese characters but its changed use was written in Korean characters. In such cases when a plot changed its territory due to merging, dividing, or road intervention, a new label was placed in the center of the new territory. If a plot had a territory too small or narrow to insert its label, an identifying symbol was added next to it, and its label was written on the margin of the map in association with the same symbol. The cadastral map contains only 14 years of records, but it was the critical period where the modern street network and the land zoning concept were established in the town. We traced the original land uses in 1971 before urbanization by carefully reading these superimposed layers of records. Another challenge was to stitch multiple maps together. Since a single cadastral map only covers a small area that can fit in on A4-sized paper, it was necessary to connect five maps together to generate a single view of the whole block. In doing so, there had to be many corrections and revisions due to the innate mismatches, distortions, and errors in the hand-drawn maps.

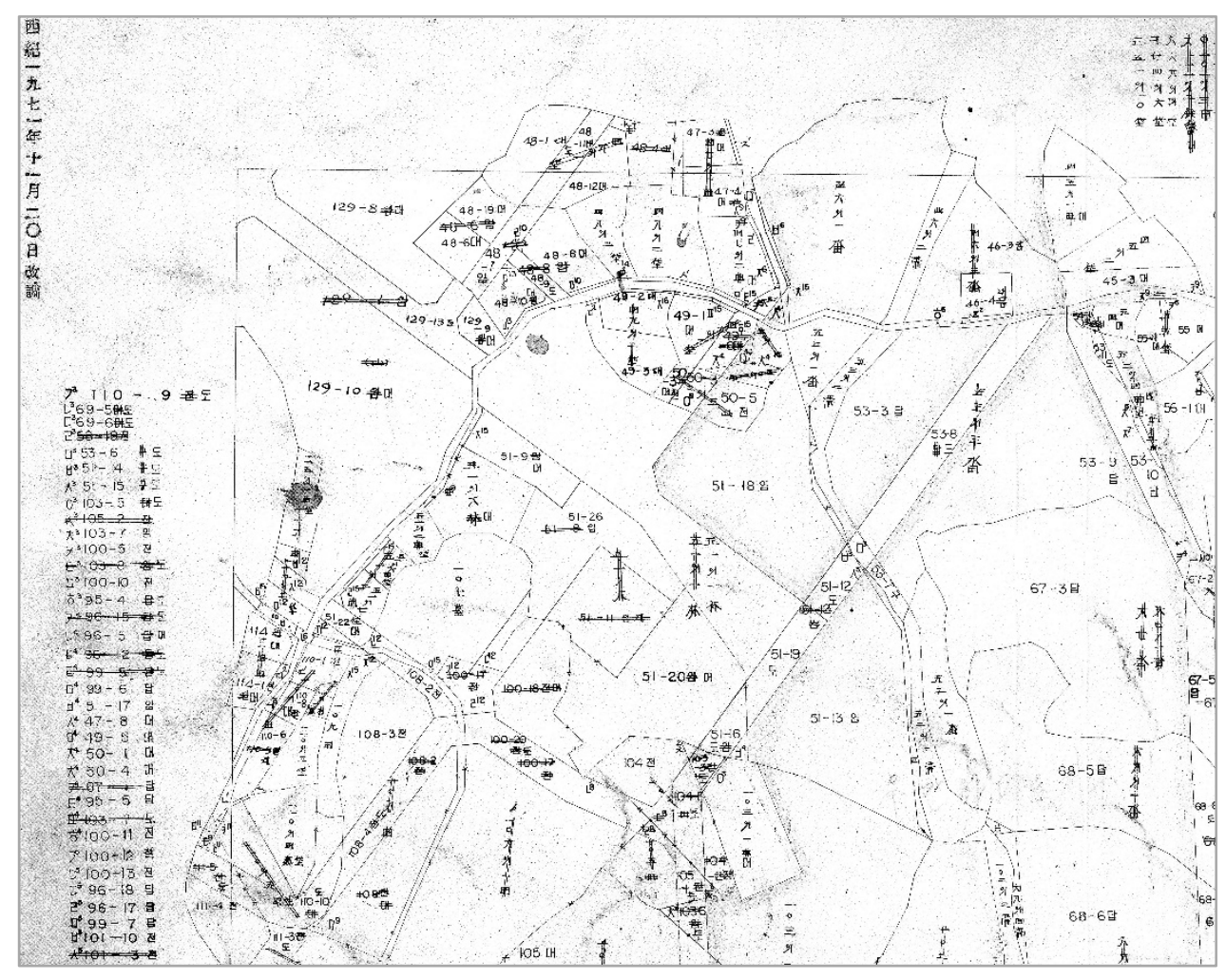

Figure 3. Part of the cadastral map of Wooman showing the record from as early as 1971 up to 1985; the Chinese characters on the upper left corner denote that the map was first issued in $20^{\text {th }}$ of November, 1971 - source: issued by the City of Suwon on 19 September 2018.

\subsection{Measuring the Performance of the Modern Street Network}

\subsubsection{Static Snapshots of Pedestrian Movement}

To investigate how a rural route operates in the modern urban setting, it is necessary to obtain real-world data on the pedestrian movements in its current context. For this, we used an observation 
technique called static snapshots. This method is a way of recording pedestrian movements and static activities on a map at a given time of the day for a full static overview of the target area as if it were a camera photo taken from above [33]. Such a map is most useful "for noting the pattern of density rather than for precise recording of numbers" [34]. The target area in Wooman was broken up into 8 sections, and each section was fully recorded by an observer within $3 \mathrm{~min}$. Two categories were applied: standing and walking, and they were color-coded in blue and red, respectively, on the final snapshot map. Two sets of observations were executed. The first observation was made on Friday 7 pm, 19th December in 2012, and the second on Saturday 5 pm, 20th December in 2012 to determine the difference in pattern during weekdays and weekends. The resulting data were digitalized on a computer-aided design (CAD) drawing.

\subsubsection{Angular Shortest Path Betweenness}

After observation of the pedestrian movements in the Wooman block, the performance of the street network was measured using the index "betweenness centrality." This is a measure that captures the importance of a vertex (each street segment in our analysis) in a given network system that serves as a throughway for the shortest paths [35]. In a network consisting of a set $V$ of vertices, betweenness centrality is defined as

$$
C_{B}(v)=\sum_{s \neq v \neq t \in V} \frac{\sigma_{s t(v)}}{\sigma_{s t}}
$$

$\sigma_{\text {st }}$ denotes the number of shortest paths from $s \in V$ to $t \in V$; and $\sigma_{s t(v)}$ those with $v \in V$ lies on.

To refine the precision of the measurement, we added the weighting of angularity between street segments, which has been effective in explaining aggregate pedestrian navigation and wayfinding [36-38]. For example, as one navigates, a turn of 90 degrees is weighted 1 as a one-step movement, while that of 45 degrees is weighted 0.5 as a half-step movement. Thus, the shortest path is the one that minimizes the total amount of accumulated angles during the journey. This measure is known as angular shortest path betweenness in network analyses, but we will simply call it angular betweenness in this paper. If a street segment has a high angular betweenness, the street is lying on many shortest paths in the given area, potentially resulting in more traffic. DepthmapX, a multi-platform open-source network analysis software, was used for the measurement [39]. The result was presented as a color-coded map to show the distribution of values in the target area.

\section{Results}

\subsection{Oxcart Route that Survived the Radical Transformation}

As discussed in Section 2.2, the earliest maps that show the pre-urbanization landscape of Wooman with reliable detail were a topographic map in 1974 and a cadastral map in 1971. Map (a) in Figure 4 is the topographic map showing how the village was settled in a hilly area. Map (b) on the right is the current digital map of the same area. For easy comparison, the current boundary of the block is marked on the 1971 map with blue lines. In the 1960s, major arterial roads were constructed on the south and east edges of the village, defining some of the current block boundaries.

The village maintained a normal agricultural life until the 1970s. Farmhouses were scattered along the edge of the woodland, which is colored green on the map. The blue ellipses on the map show the four major clusters of farmhouses. The village was linked internally and externally by oxcart roads (thick red lines) and walking paths (dotted orange lines). It seems that the internal communication of the village, especially between the four residential clusters, depended largely on the circulation route, which resembles a brimmed hat. This inner circulation route will be called the "oxcart route" in the rest of the paper. Running along the valley, down to the low land at the bottom were stepped paddies that used hydroponics for production of rice. The location of the farmhouses is typical for an agricultural village in Korea in that they are built between the woodland and farmland. It is a natural 
solution to build them nearer to rice paddies, where farmers spend most of their day, yet on higher ground along the edge of woodland to avoid dampness and to get easy access to woodland products such as firewood and vegetables.

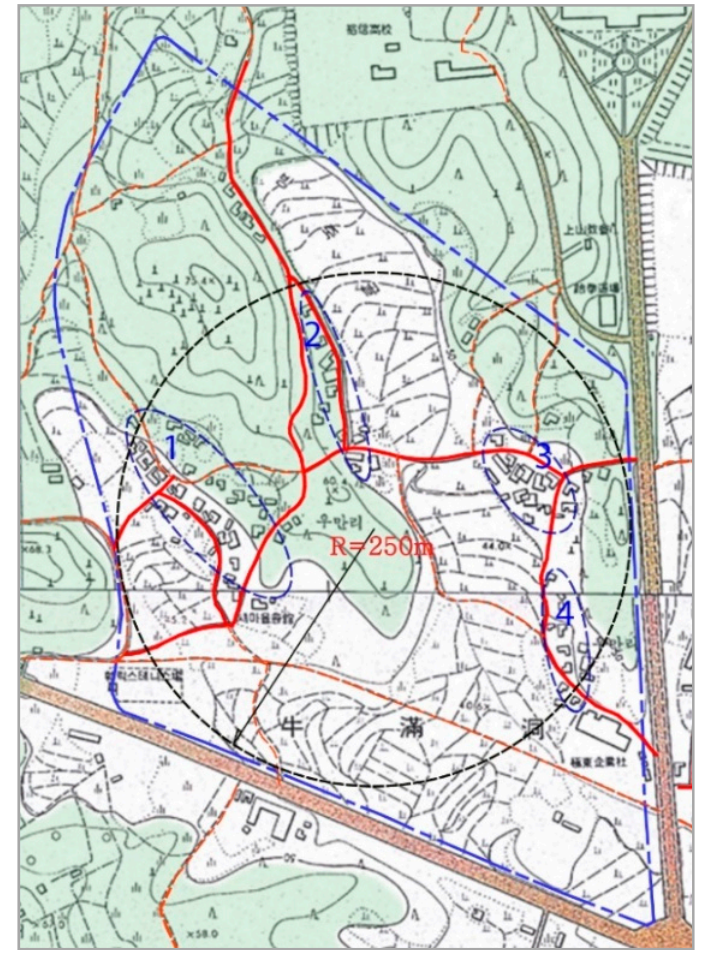

(a)

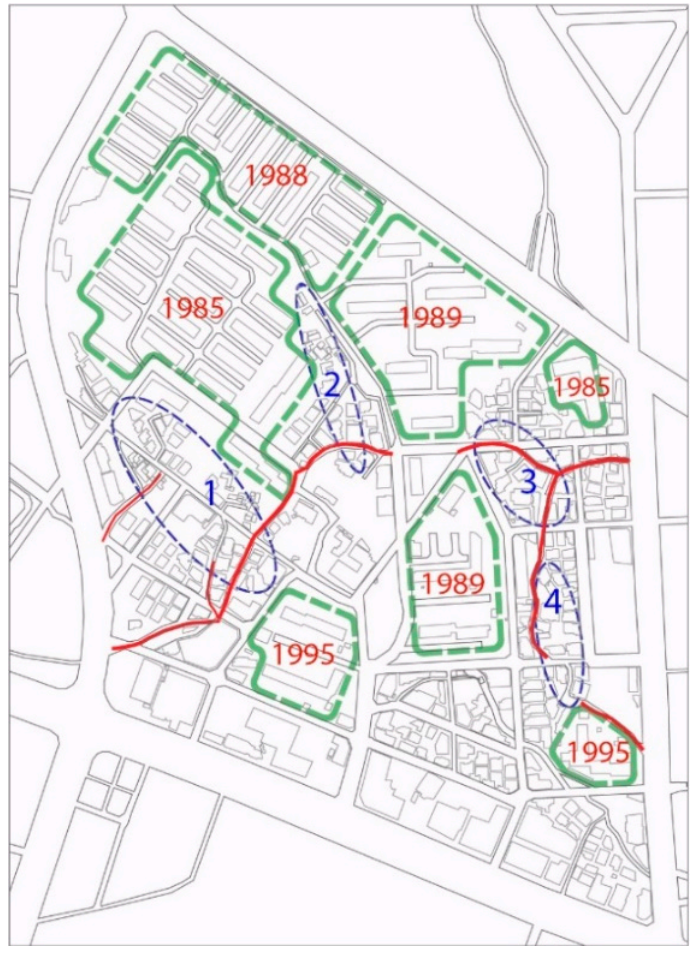

(b)

Figure 4. (a) Wooman old topographic map of 1974 with oxcart roads (red), walking paths (orange), and farmhouse clusters (blue ellipses); (b) Map from 2016 with remaining traces of the old roads (red), apartment housing estates (green dotted lines), and mapping of farmhouse clusters from the 1974 map (blue ellipses)—source: modified from the original topography map issued by the City of Suwon in March 2013.

In the mid-70s, Wooman went through a radical transformation from a quiet agricultural village to a busy and compact urban town, with its population reaching 18,764 in 2013-14 times larger than that of 1974. By superimposing the old and new maps, it was possible to detect the remaining rural paths on the current map. Surprisingly, the oxcart route from the 1974 map is almost intact, with only two short missing links. Most of the paths branching out of the oxcart route have disappeared, but this internal circulation route persisted. The territories marked by green dotted lines in the 2016 map are apartment housing estates, and their construction years are written at the center of each territory. An interesting pattern was found by relating them with the traces of the oxcart route and the four house clusters. Although the apartment housing estates occupy much larger areas of land, they never push their territories over the domain of the old house clusters and the oxcart route. For some reason, the main spatial structure of the old village escaped the brutal force of massive urban development. How was it possible that they outlived such radical change? Has this happened by human intention or by coincidence? The key to the answer was the cadastral map, a public record of land use and ownership.

\subsection{Influence of Land Types on the Land Acquisition Process for Developments}

To construct new housing on woodland or farmland, the first step is to go through an administrative procedure of converting the land use to residential plots. If that happened in Wooman, then the cadastral map might provide some clues as to why the developers avoided the existing residential plots while prioritizing other land types. To enable this, key information from the 
topographic map and modern digital map was superimposed onto the cadastral map as precisely as possible. Five separate maps were stitched together to get a single view of the whole block (Figure 5). The earliest cadastral record registered in 1971 was traced and highlighted. The four land use types are marked differently following the legend at the bottom left corner in the figure. Light green is for woodland, light blue for farmland (paddies and fields), and light red for residential plots. The organic shape of the oxcart route is clearly visible, and there is a watercourse flowing from north to south following the decreasing steps of the paddies. When all the farmhouses in the 1974 topographic map were mapped onto this cadastral map, they fell on the residential plots with minor exceptions. This means that most of the farmhouses in the 1974 topographic map already had their lands registered as residential use by 1971. When the territories of the apartment housing estates from the 2016 map were superimposed (red dotted lines), they rarely touch these houses, confirming the data shown in Figure $4 b$.

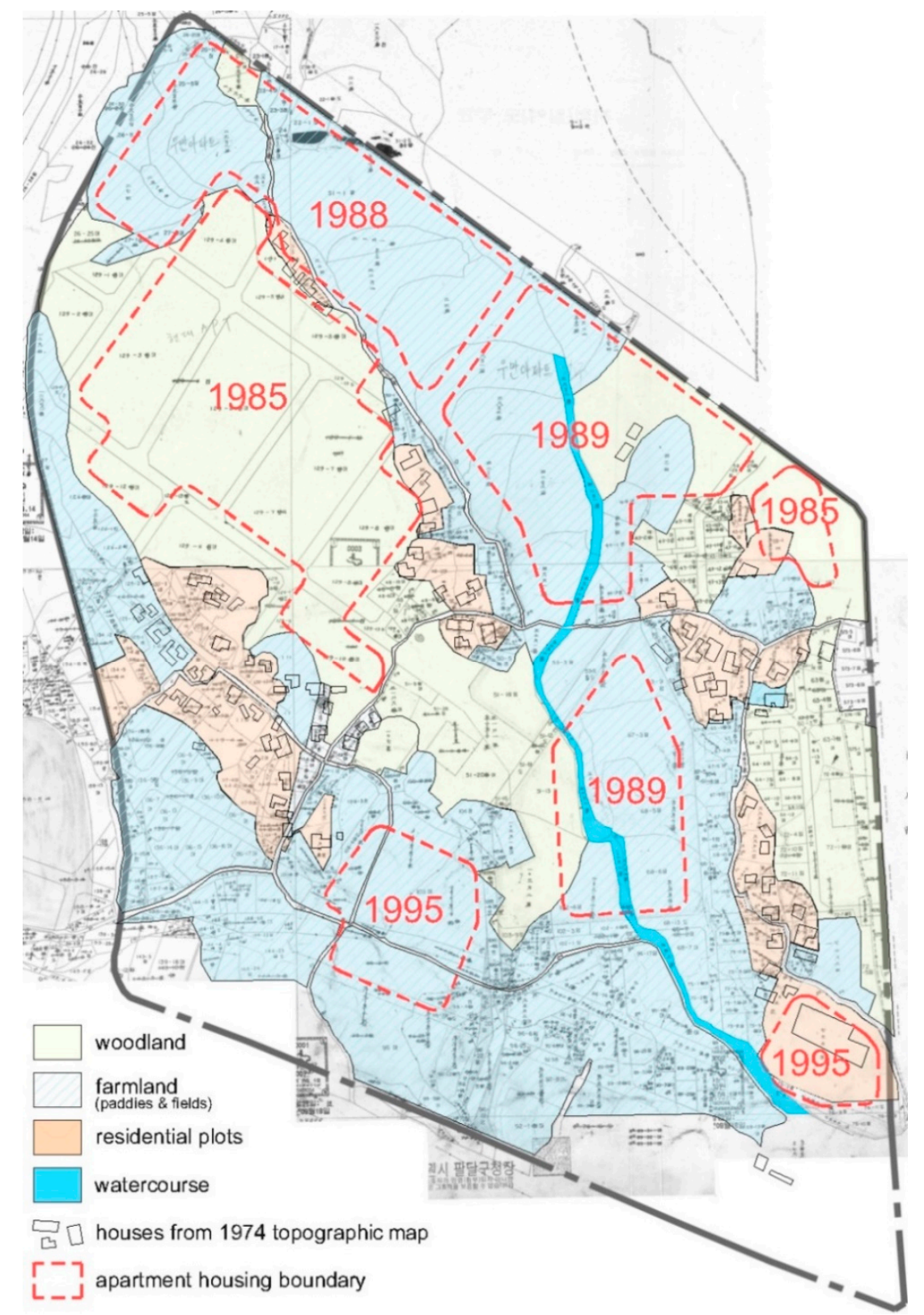

Figure 5. Cadastral map of Wooman with color-coded land types-source: modified from the original cadastral maps issued by the City of Suwon on 19 September 2018. 
Intriguingly, a meaningful pattern was found when the construction years of the apartment housing estates were compared with the original land use of their sites. The first development was the Hyundai apartments built in 1985, with 17 5-story buildings. The land they acquired was woodland. In Figure 5, there are four sections of woodland, disconnected from roads and other types of lands. As expected, the section they chose was the biggest one, on the northwest side of the village. The map indicates that the developer tried to maximize the buildable area within the boundary of the woodland, resulting in a wavy estate boundary. In contrast, the streets inside the estate show an organized grid pattern. Another estate was developed in the same year of 1985 in the northeast corner of the block, consisting of a single 5-story building on a relatively small woodland plot, but its boundary included a patch of residential land. After several years, in 1988 and 1989, three sites were developed by the Korea Housing Corporation, a public company designated to build and supply houses. The 1988 scheme had 135 -story buildings, and the 1989 scheme had eight 14-story buildings on two separate sites. This time, the land they chose was mainly farmland, combined with some woodland. During this period, the modern road network was marked on the cadastral map, although not fully constructed, so the boundaries of the new developments align with this network rather than the irregular shapes of land lots. Finally, in 1995, two construction companies, Sunkyung and Samsung, completed two small apartment housing schemes. The former had two 18-story buildings on a farmland plot, while the latter had one 15-story building on a residential plot, which is the land type avoided by the previous projects.

Looking at the seven apartment housing developments, it is obvious that the developers prioritized woodland over other land types, and farmland was their second choice. For some reason, residential plots seemed to be the last resort among land types. Presumably, this clear order of preference has some connection to their profit or project implementation. The Bank of Korea recently published a chronological review of land prices in South Korea [40]. Although the report does not show price distribution by cities, one of its most important findings was that the price ratio among land types was nearly constant across the nation over the period of data analysis, from 1964 to 2013. Assuming the developers started to procure lands in Wooman immediately after the Residential Development Promotion Law became effective, the national land price averages in 1980 can be an indicator of their procurement behaviors. The average prices per square meter for the land types in 1980 in Korean Won were 241 (woodland), 3094 (paddies), 2182 (fields), and 23,893 (residential). In approximation, their cost ratios are 1:13:9:99. Roughly speaking, woodland is 10 times cheaper than farmland (paddies and fields), and farmland is 10 times cheaper than residential plots. Supposedly, the developer will make 100 times greater profit when buying woodlands and converting them to residential lands. With no more woodland to secure, the second choice is farmland, with residential plots as the last choice. This explains why the first development in Wooman used the biggest section of woodland and the following ones moved to farmland and then to residential plots.

Apart from the economic motivation, there are two additional reasons that explain why the clusters of residential plots remained intact: the complexity of land acquisition and place attachment. The cadastral map reveals that land lot size varies greatly by land type. Comparing the average sizes of registered land areas, we found that woodland was the biggest, farmland was in the mid-range, and residential land was the smallest. Consequently, it is much easier for developers to deal with a small number of woodland owners when securing the required amount of land. In addition to this technical reason, there also exists a human factor of place attachment, which is even more complicated. In agricultural villages, it is common that people spend their entire lives in the village where they were born, and this helps to develop a sense of belonging. This place attachment can act as the strongest motivation when deciding to sell their land and houses. It might have been that the villagers sold some of their woodland and farmland for the financial reward, but many of them were probably reluctant to leave their home. As a result, the procedural hurdle of negotiating with many individuals who have a strong attachment to their homes could have allowed the old housing clusters to remain during the process of radical development. 
It is impossible to know exactly what happened behind the scenes in the massive transformation in Wooman between 1974 and 2013. The maps examined can only provide possible scenarios. The cadastral map in Figure 5 reveals a clear difference in the speed of change by land type. Higher land prices, the complexity of acquisition, and residents' attachment to their homes could have acted together to slow the change in residential lands. Grouped together as clusters, this resistance to change could have been even stronger. In this vein, the oxcart route that interweaves the residential clusters could have higher chances of survival, while other roads were destroyed by the developers. At least one generation has passed since the urbanization in Wooman. There is not a single house left from the old village; they were all demolished and replaced by new buildings. Only the oxcart route remains, providing a clue to life in a quiet agricultural village.

\subsection{Potential Power of the Oxcart Route in the Modern Network}

\subsubsection{Pedestrian Movements}

Modern Wooman has an urban fabric packed with small and large buildings on a complex street network that is significantly different from the rural road system. Figure 6 shows the results from two observations of static snapshots made on Friday 7 pm, 19th December (a) and Saturday 5 pm, 20th December (b) in 2012. Red dots represent people walking, and blue dots are those standing. The sizes of the dots are proportional to the number of people.

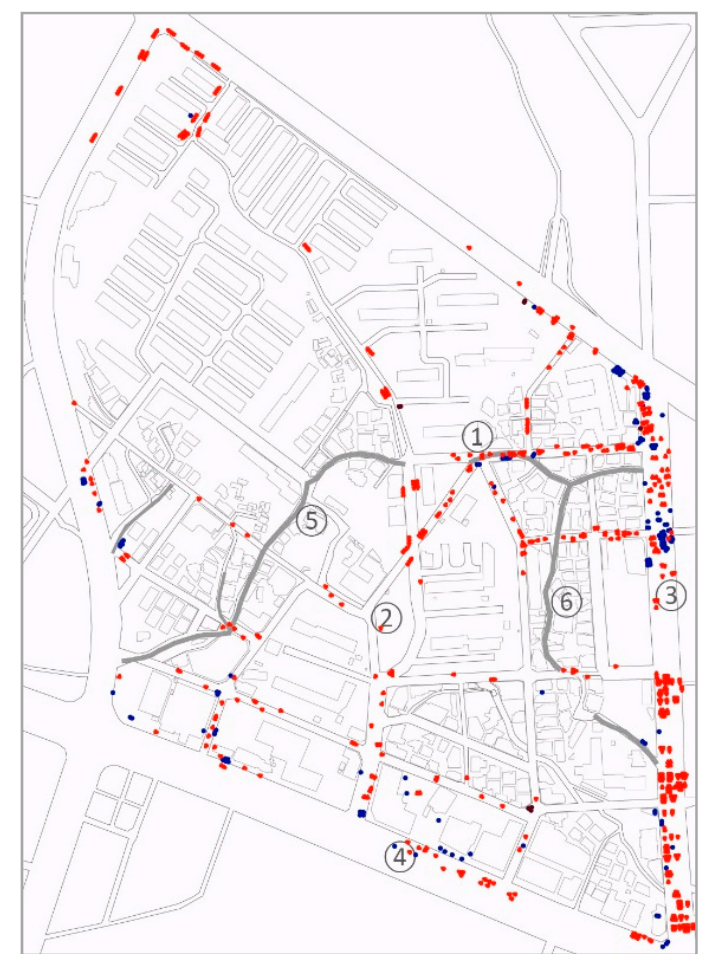

(a)

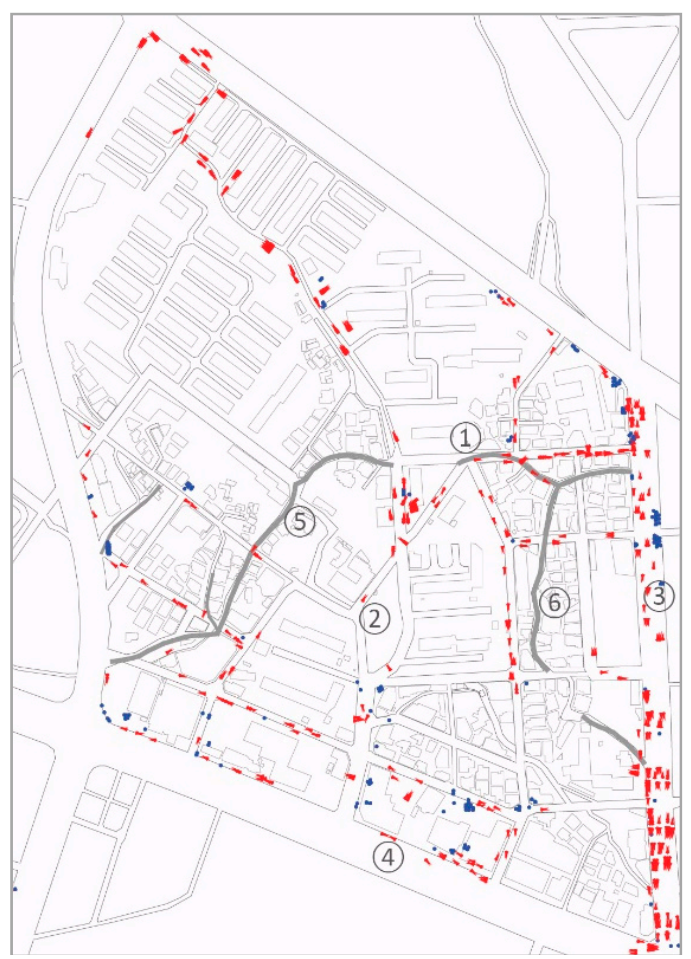

(b)

Figure 6. Static snapshots of pedestrian movements: (a) on Friday 7pm 19 December 2012 and (b) on Saturday 5pm 20 December 2012—source: drawn by the author.

The snapshot on Friday shows that the road on the right edge of the block, road 3, is the busiest, followed by a few other internal branching streets, especially road 1 . This is an expected outcome since these streets have many restaurants and cafeterias frequented by the students and staff from the university nearby. Also, the results could have been influenced by observation on a Friday at $7 \mathrm{pm}$, which is the onset of nightlife. While there are some movements on the other parts of the block, the streets inside the apartment housing estates show almost no movement. Likewise, the oxcart route 
(colored grey) has only a few people on it, except for the short section merged with the straight modern street, road 1.

Another observation was made on Saturday $5 \mathrm{pm}$, and was thought to reveal different movement patterns of daytime activities during weekends [Figure 6b]. The result shows that pedestrian movements have been reduced around the busiest roads (road 1 and 3) but increased around the residential areas. However, the overall pattern is not much different from that of Friday. In particular, the oxcart route is still almost empty-only walked on by a few more people than on Friday. Unlike the internal roads inside the apartment housing estates, it is not just an access route to the residences alongside it but provides "through movements" to the other parts of the block. The two snapshots confirm the under-use of the street. It seems that the oxcart route-which once functioned as the most important spatial device for communication in the village- has been fossilized and abandoned inside the modern street network. Is this old route becoming redundant in the modern context, or does it retain potential usefulness for the network?

\subsubsection{Oxcart Route as an Effective Local Connector}

To test the potential value of the oxcart route in supporting the network flow of modern Wooman, the "angular shortest path betweenness" (or "angular betweenness" for short) was calculated using the DepthmapX software [38]. This measure is known to quantify the potential for each road segment, i.e., the road between two intersection points, to lie on the shortest paths for all pairs of origins and destinations in the system, as discussed in Section 2.3.2. Hence, angular betweenness shows the potential of a road segment to be used for "through movements" for the shortest angular journeys within a given spatial network.

Figure 7 shows two results of angular betweenness. Map (a) shows global movements, and map (b) shows local movements. The difference between global and local movements lies in distance limits for trips. If there is no distance limit, the analysis will show the pattern of global movements between all street segments in the block-indicated as radius $\mathrm{n}$. If there is a limit, say $250 \mathrm{~m}$ for each trip, the analysis will show the pattern of local movements up to that distance-indicated as radius 250. The calculated value for each street segment is coded in color on the map. The highest value is rendered in red, followed by orange, yellow, green, and blue in descending order. The global analysis in Figure 7a shows red segments (highest values) around the center-around road 1 and junction 2. Orange segments (higher values) are seen on roads 3 and 4 on the outer edges of the block. These highest and higher values include the two busiest roads, roads 1 and 3 , in the snapshot maps in Figure 6. Also, the blue streets with the lowest values are those with almost no pedestrians in the snapshot maps. This result indicates some degree of correlation between observation and simulation, confirming under-use of the oxcart route (road 5 and 6 ) to attract pedestrians, except for road 1 , which has been merged with a straight modern road.

Different radii were tested to simulate potential local movements. When the radius was set to $250 \mathrm{~m}$, the angular betweenness analysis generated an unexpected pattern [Figure $7 \mathrm{~b}$ ]. At this radius, the oxcart route is highlighted by red, orange, and yellow, displaying the shape of a brimmed hat. In old Wooman, as discussed in Figure 4a, the boundary of a $250 \mathrm{~m}$ circle enclosed the house clusters and the oxcart route connecting them. It is surprising that within the scale of the old village, the oxcart route preserves its potential power to optimize local movements. Because it is traversing the grid at different angles (rather than orthogonal angles), short trips inside the block can be even shorter by following this hidden alley. Apparently, the shortest trips within the circle of $250 \mathrm{~m}$ radius are not for urban-scale movement. Rather, it is for communication between neighbors within the community. As in the snapshot observation, the reason the old route is not chosen in real life is that there are many alternative routes competing with it with better walking environments. There are many problems with the old roads that deter pedestrians: randomly built houses, no pavement to protect pedestrians from cars, illegal parking, and waste dumping. Therefore, providing a walkable environment is the key to revitalizing these old roads. Furthermore, old roads can offer more than the functional benefit of 
shortcuts from a socio-cultural perspective. In the neutral environment of the modern grid system, their organic irregularity is important material evidence that shows the history of a place. It can further help revive the lost identity of the town. The angular betweenness analysis above demonstrates that old traces in the new setting may retain more practical value than expected. Once we begin to look at them as an asset, rather than redundancy or inefficiency, it is possible to explore their positive impact on our way of making livable and sustainable places and communities.

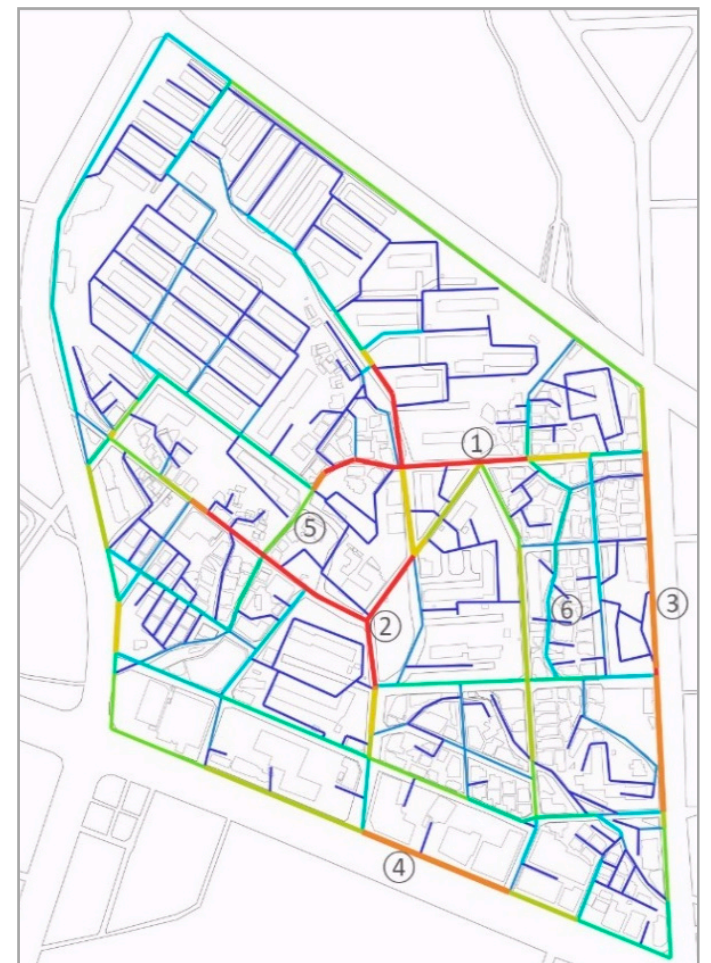

(a)

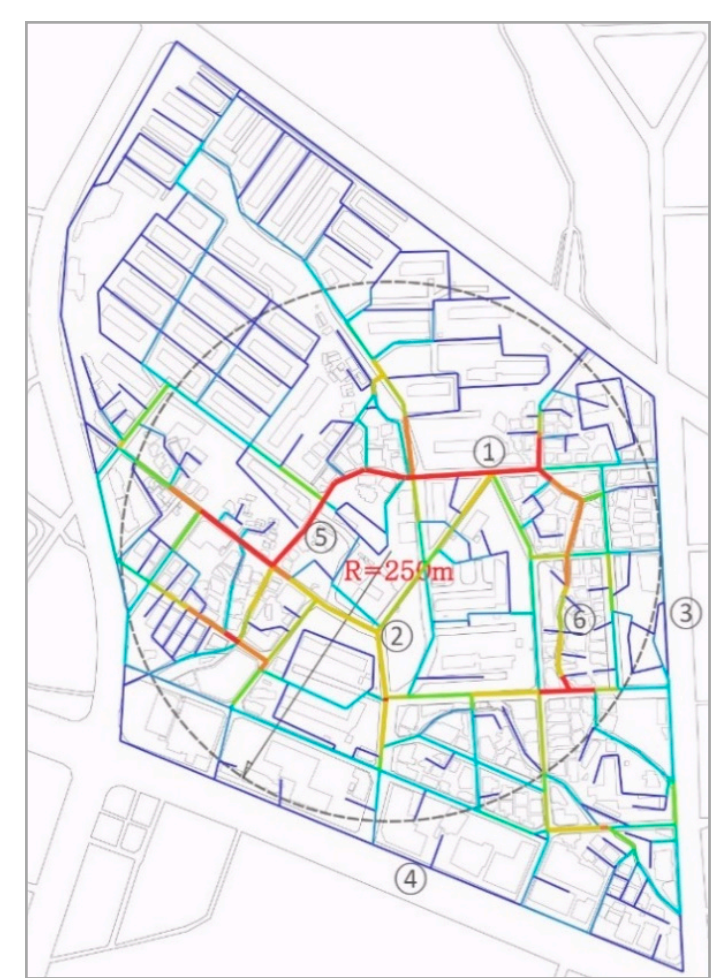

(b)

Figure 7. Angular shortest path betweenness calculated with two different radii: (a) Radius $\mathrm{n}$ and (b) Radius 250- source: drawn by the author.

\section{Discussion}

This paper illuminated the typical process of urbanization in Korea to determine why some old streets survive inside the dense fabric of a new urban block. This research used the case of Wooman, a town in Suwon, but it is a common phenomenon across the nation. Major cities underwent a period of expansion from the 1970s until the 1990s when massive housing developments wiped out the existing rural landscape on the periphery of the cities. The generic transformation process of an agricultural village during urbanization can be diagrammed as a conceptual model (Figure 8). It shows four phases of transformation where a rural village is gradually converted to a modern block.

In the first phase, farmhouses are built on the edge of the woodland looking down onto farmland, which is mainly rice paddies. These farms are clustered to form a hamlet and then a small village. Rural roads are naturally grown to connect houses and other frequent destinations. By the time land ownership is registered on cadastral maps, plot boundaries are delineated (pink dotted lines), and land types are determined. The price per square meter by land type follows the descending order of residential lands, farmland, and woodland, while average lot sizes decrease in the reverse order. In the second phase, urbanization starts with the development of apartment housing exclusively on woodland, mainly because its unit price is the cheapest and because its procurement process is easier since a smaller number of people tend to own a large quantity of land. Modern roads are connected to the village to enable large-scale development. 


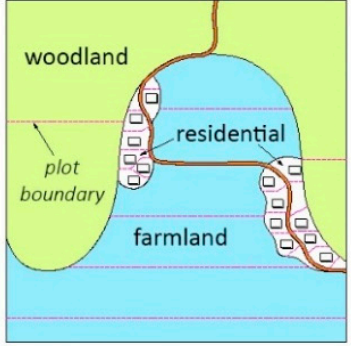

phase 1: agricultural village

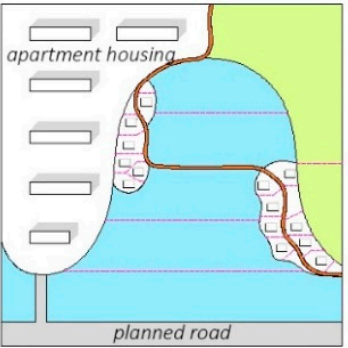

phase 2: urbanisation starts

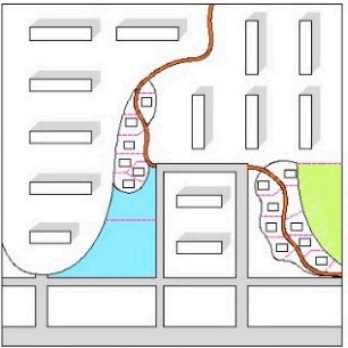

phase 3: more developments

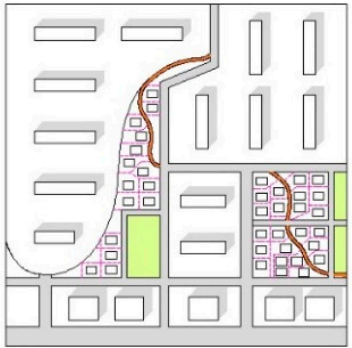

phase 4: urbanisation complete

Figure 8. Conceptual model showing the four phases of urbanization of a rural village-source: drawn by the author.

In the third phase, more housing developments follow, along with additional road connections. Woodland is consumed quickly, after which farmland, which is the second cheapest, becomes the next target. As residential plot owners are the most resistant to new development, their houses remain longer and are eventually surrounded by tall apartment buildings. In this stage, planning concepts such as road networks and land use zoning are introduced. In the final fourth phase, the village is further filled with commercial and residential buildings, becoming a fully integrated part of the city. The road network and land use zoning are finalized, resulting in fossilization of some of the irregular shapes of old residential plots and rural roads inside the urban block.

Figure 9 shows another example in Yeoksam-dong, Seoul that followed the same pattern of radical urbanization of a rural village. In the modern map (a), the area inside the dotted circle shows a cluster of organic roads forming a unique pattern of concentric curves that does not follow the global order of the grid system. Figure $9 \mathrm{~b}$ is an aerial photo of the block in 1972 when the whole area was under massive development to build a new southern extension of Seoul, namely Gangnam. It is evident that the organic road pattern in the current map is based on the rural village, wherein the farmhouses were almost intact in the 1972 photo, while the surrounding area was undergoing complete re-configuration. Comparing various maps and photos, it is possible to confirm that the remaining organic road pattern is identical to the spatial structure of the old streets inside the house cluster. Also, the diagonal roads, another anomaly in the grid system, originated from the existing axis of the old watercourse, as indicated by the arrow in the 1972 photo.

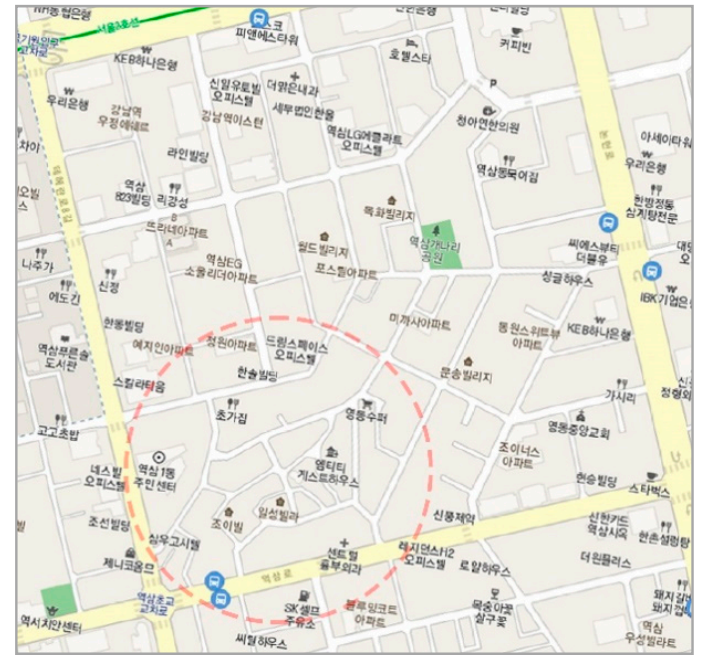

(a)

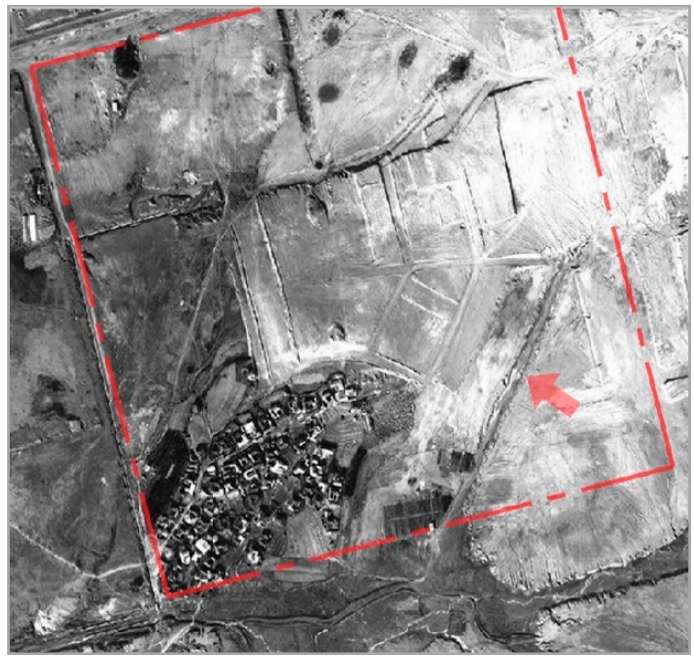

(b)

Figure 9. Change in the street network of Yeoksam-dong: (a) Street map of 2016 after full development-source: Daum map, http: / / map.daum.net; (b) Aerial photo taken in 1972 showing the early stage of development—source: aerogis.seoul.go.kr, copyright (C) 2011 Seoul Metropolitan Government. 


\section{Conclusions}

During urbanization in Korea, rural roads that remained in the modern grid system were treated as something that ruined the modern ideal of efficiency and visual clarity and should be eliminated. For developers and planners, it was not desirable that the geometric order of a street network interfere with and be deformed by fragments from the past. Nevertheless, this unwelcomed legacy made its way into many modern cities due to the disparity in land size and price, combined with local resident resistance to sell. Once left inside the modern block, old roads do not exhibit as much influence as they did and are quickly relegated to back alleys, functioning merely to provide access to the houses alongside them. However, as the network analysis showed, they have the potential to hold an important role as local connectors in the neighborhood, especially within the scale of the old village. More importantly, old roads in the modern grid can be a rare asset that brings back old memories and re-generates the identity of the town. They are the unexpected heritage that serves as landmarks to help nurture lost attachment to the place. In the age of tourism and storytelling, they are the best narrative a town can possess. It is ironic that this spatial kernel of the old village has been unintentionally preserved in the heart of the urban block.

Using an archival investigation and mapping, this research illuminated the urbanization process in the rural area to show how old roads have been fragmented and fossilized inside a modern city. We focused on a small village in Suwon, but, as discussed in this section, it provides a convincing conceptual framework to effectively explain the common phenomenon of an old trail inside the modern block that can be discovered in most major cities in Korea. Although this paper shed light on the subject, which has been given little attention due to the subordinate nature of small-scale land transactions behind the large-scale developments, its verification was based on archival records of maps and documents. Therefore, this paper has not provided the ethnographic dimension to address the actual execution of the development based on the perspective of those who were involved in it. It would be difficult to identify the behavioral patterns of the participants behind the mega-scale urbanization. However, by tracing the records of land acquisition by the developers and landowners (especially during the period when the Residential Development Promotion Law was in effect), a further study could establish a more systematic and triangulated view of the transformation of the rural landscape in Korea.

Author Contributions: K.W.S., the leading author, initially conceived and designed the research. He also executed data analyses and prepared the original draft. S.L., a corresponding author, provided data, reframed the research structure, and revised the draft.

Funding: This research received no external funding.

Conflicts of Interest: The authors declare no conflict of interest.

\section{References}

1. Choi, C.G.; Lee, S. Suburbanization in Asia: A Focus on Seoul. In Suburbanization in Asia: A Focus on Seoul Suburbs. The Routledge Companion to the Suburbs; Taylor \& Francis Group, Routledge: New York, NY, USA, 2019.

2. Korean Statistical Information Service (KSIS). Population Census, 1966-2016. 2017. Available online: http://kosis.kr/index/index.jsp (accessed on 8 March 2017).

3. Choi, C.G.; Lee, S.; Kim, H.; Seong, E.Y. Critical Junctures and Path Dependence in Urban Planning and Housing Policy: A Review of Greenbelts and New Towns in Korea's Seoul Metropolitan Area. Land Use Policy 2018, 80, 195-204. [CrossRef]

4. Ravetz, J.; Fertner, C.; Nielsen, T.S. The Dynamics of Peri-Urbanization. In Peri-Urban Futures: Scenarios and Models for Land Use Change in Europe; Springer: Berlin/Heidelberg, Germany, 2013.

5. García-Ayllón, S. Rapid Development as a Factor of Imbalance in Urban Growth of Cities in Latin America: A Perspective based on Territorial Indicators. Habitat Int. 2016, 58, 127-142. [CrossRef] 
6. Smith, N.R. Beyond Top-down/Bottom-up: Village Transformation on China's Urban Edge. Cities 2014, 41, 209-220. [CrossRef]

7. Chen, L.; Ren, C.; Zhang, B.; Wang, Z.; Liu, M. Quantifying Urban Land Sprawl and its Driving Forces in Northeast China from 1990 to 2015. Sustainability 2018, 10, 188. [CrossRef]

8. Kontgis, C.; Schneider, A.; Fox, J.; Saksena, S.; Spencer, J.H.; Castrence, M. Monitoring Peri-urbanization in the Greater Ho Chi Minh City Metropolitan Area. Appl. Geogr. 2014, 53, 377-388. [CrossRef]

9. Seto, K.C.; Fragkias, M.; Güneralp, B.; Reilly, M.K. A Meta-analysis of Global Urban Land Expansion. PLoS ONE 2011, 6, e23777. [CrossRef] [PubMed]

10. Statuto, D.; Cillis, G.; Picuno, P. Analysis of the Effects of Agricultural Land Use Change on Rural Environment and Landscape through Historical Cartography and GIS tools. J. Agric. Eng. 2016, 47, 28-39. [CrossRef]

11. Tian, L.; Ge, B.; Li, Y. Impacts of State-led and Bottom-up Urbanization on Land Use Change in the Peri-urban Areas of Shanghai: Planned Growth or Uncontrolled Sprawl? Cities 2017, 60, 476-486. [CrossRef]

12. Van Vliet, J.; de Groot, H.L.; Rietveld, P.; Verburg, P.H. Manifestations and Underlying Drivers of Agricultural Land Use Change in Europe. Landsc. Urban Plan. 2015, 133, 24-36. [CrossRef]

13. Webster, D.; Cai, J.; Muller, L. The New Face of Peri-urbanization in East Asia: Modern Production Zones, Middle-class Lifestyles, and Rising Expectations. J. Urban Aff. 2014, 36 (Suppl. 1), 315-333. [CrossRef]

14. Shatkin, G. The Real Estate Turn in Policy and Planning: Land Monetization and the Political Economy of Peri-urbanization in Asia. Cities 2016, 53, 141-149. [CrossRef]

15. García-Ayllón, S. Predictive Diagnosis of Agricultural Periurban Areas Based on Territorial Indicators: Comparative Landscape Trends of the So-Called “Orchard of Europe. Sustainability 2018, 10, 1820. [CrossRef]

16. Huang, S.L.; Wang, S.H.; Budd, W.W. Sprawl in Taipei's Peri-urban Zone: Responses to Spatial Planning and Implications for Adapting Global Environmental Change. Landsc. Urban Plan. 2009, 90, 20-32. [CrossRef]

17. Jacquin, A.; Misakova, L.; Gay, M. A Hybrid Object-based Classification Approach for Mapping Urban Sprawl in Periurban Environment. Landsc. Urban Plan. 2008, 84, 152-165. [CrossRef]

18. Statuto, D.; Cillis, G.; Picuno, P. Using Historical Maps within a GIS to Analyze Two Centuries of Rural Landscape Changes in Southern Italy. Land 2017, 6, 65. [CrossRef]

19. Rauws, W.S.; de Roo, G. Exploring Transitions in the Peri-urban Area. Plan. Theor. Pract. 2011, 12, $269-284$. [CrossRef]

20. Conzen, M.R.G. Alnwick Northumberland: A Study in Town-Plan Analysis; Institute of British Geographers Publication 27; Institute of British Geographers: London, UK, 1960.

21. Marshall, S.; Çalişkan, O. A Joint Framework for Urban Morphology and Design. Built Environ. 2011, 37, 409-426. [CrossRef]

22. Cowan, R. The Dictionary of Urbanism; Streetwise Press: Tisbury, UK, 2005.

23. Lozano, E. Community Design and Culture of Cities; Cambridge University Press: Cambridge, UK, 1990; p. 209.

24. Urban Morphology Research Group (UMRG) Glossary. Available online: http://www.urbanform.org/ glossary.html (accessed on 14 February 2019).

25. Moudon, A.V. Urban Morphology as an Emerging Interdisciplinary Field. Urban Morphol. 1997, 1, 3-10.

26. Oliveira, V. Urban Morphology: An Introduction to the Study of the Physical Form of Cities; Springer International Publishing: Cham, Switzerland, 2016.

27. Kostof, S. The City Shaped: Urban Patterns and Meanings through History; Bulfinch: New York, NY, USA, 1991.

28. Kropf, K. The Handbook of Urban Morphology; John Wiley \& Sons Ltd.: West Sussex, UK, 2017.

29. Jin, Y.-H.; Ahn, K.-H. Types and Characteristics of Historic Urban Form Changes in City Center of Seoul. J. Urban Des. Inst. Korea 2009, 10, 103-120.

30. Kim, D.N.; Bae, W.K.; Sung, J.U. Analysis of Urban Form Transformation for a Decade of Old Block in the Downtown of Seoul, Korea. Seoul Stud. 2010, 11, 99-117.

31. Suwon City. The 53rd Suwon Statistics Report. Available online: www.suwon.go.kr (accessed on 21 September 2018).

32. Suwon City. Statistical Yearbook of Suwon 1974. Available online: www.suwon.go.kr (accessed on 21 September 2018).

33. Al_Sayed, K.; Turner, A.; Hillier, B.; Iida, S.; Penn, A. Space Syntax Methodology, 4th ed.; Bartlett School of Architecture, UCL: London, UK, 2014; Unpublished Manual. 
34. Grajewski, T. Observation Manual, in Space Syntax Software Manuals, 2001 ed.; Vaughan, L., Stutz, C., Eds.; Bartlett School of Architecture, UCL: London, UK, 2001; Unpublished Manual.

35. Freeman, L.C. A Set of Measures of Centrality Based on Betweenness. Sociometry 1977, 40, 35-41. [CrossRef]

36. Penn, A.; Hillier, B.; Banister, D.; Xu, J. Configurational Modelling of Urban Movement Networks. Environ. Plan. B 1998, 24, 59-84. [CrossRef]

37. Dalton, R. The Secret is To Follow Your Nose: Route Path Selection and Angularity. Environ. Behav. 2003, 35, 107-131. [CrossRef]

38. Hillier, B.; Yang, T.; Turner, T. Normalising Least Angle Choice in Depthmap and How It Opens Up New Perspectives on the Global and Local Analysis of City Space. J. Space Syntax 2012, 3, 155-193.

39. Varoudis, T. DepthmapX Multi-Platform Spatial Network Analysis Software. Version 0.3b; OpenSource. 2012. Available online: http:/ / varoudis.github.io/depthmapX/ (accessed on 10 May 2018).

40. The Bank of Korea. Estimation of the Land Asset Value of Korea Through the Chronological Analysis; Discussion Paper Series, BOKDP No. 2015-6; Bank of Korea: Seoul, Korea, 2015.

(C) 2019 by the authors. Licensee MDPI, Basel, Switzerland. This article is an open access article distributed under the terms and conditions of the Creative Commons Attribution (CC BY) license (http:/ / creativecommons.org/licenses/by/4.0/). 